Eur. J. Clin. Chem. Clin. Biochem.

Vol. 31, 1993, pp. 267-272

(C) 1993 Walter de Gruyter \& Co.

Berlin $\cdot$ New York

\title{
Degradation of Bradykinin by Neutral Endopeptidase (EC 3.4.24.11) in Cultured Human Endothelial Cells
}

\author{
By K. Graf ${ }^{1}$, M. Gräfe ${ }^{1}, C$. Bossaller ${ }^{1}$, J. Niehus ${ }^{2}$, K.-D. Schulz ${ }^{2}$, W. Auch-Schwelk ${ }^{1}$ and E. Fleck ${ }^{1}$ \\ ${ }^{1}$ Department of Cardiology, German Heart Institute Berlin, Berlin, Germany \\ ${ }^{2}$ Department of Clinical Immunology and Asthma OPD, Free University Berlin, Berlin, Germany
}

(Received June 3/November 30, 1992)

Summary: The presence of neutral endopeptidase 24.11 was demonstrated in human umbilical vein endothelial cells by immunostaining. Enzymatic activity of neutral endopeptidase was determined as $0.167 \pm 0.02 \mathrm{mU} / \mathrm{mg}$ protein in the membrane fraction of human umbilical vein endothelial cells, using the fluorogenic peptide substrate, dansyl- $D$-Ala-Gly-Phe $\left(p \mathrm{NO}_{2}\right)$-Gly. No activity was found in the cytosolic fraction of endothelial cells. The role of this peptidase in the degradation of the endogenous vasodilator bradykinin was investigated by incubating human umbilical vein endothelial cell monolayers with bradykinin $\left(10^{-8} \mathrm{~mol} / \mathrm{l}\right)$. The inhibitor of neutral endopeptidase, phosphoramidon $\left(10^{-8} \mathrm{~mol} / \mathrm{l}\right)$, decreased the degradation of bradykinin in the supernatant of endothelial cells; the half-life of bradykinin was then increased from $29 \pm 1$ to $46 \pm 2$ minutes. The angiotensin-converting enzyme inhibitor, lisinopril $\left(10^{-8} \mathrm{~mol} / \mathrm{l}\right)$, increased the half-life of bradykinin to $244 \pm 20$ minutes; the combination of both inhibitors increased the half-life of bradykinin to $381 \pm 51$ minutes. Inhibitors of aminopeptidase (amastatin) and carboxypeptidase (2-mercaptomethyl-3-guanidinoethylthiopropionic acid) caused no significant effect. The effect of phosphoramidon was small in comparison with that of lisinopril, but was pronounced in combination with lisinopril. Neutral endopeptidase activity is localized in the membranes of human endothelial cells and seems to be involved in the degradation of bradykinin by the vascular endothelium, particularly during angiotensin converting enzyme inhibition.

\section{Introduction}

The emerging importance of vasoactive peptides in the regulation of vascular tone has directed interest to enzymes which could be involved in their local generation and degradation. Bradykinin acts as a potent vasodilator by inducing the rapid release of endothelium-derived relaxing factor, nitric oxide, and

\footnotetext{
1) Enzymes

Neutral endopeptidase $=$ Membrane metallo-endopeptidase, EC 3.4.24.11

Angiotensin converting enzyme $=$ Kininase II = Dipeptidy 1 carboxypeptidase I, EC 3.4.15.1

Aminopeptidase, EC 3.4.11.11

Carboxypeptidase $=$ Serine carboxypeptidase, EC 3.4.16.1
}

prostacyclin from vascular endothelial cells (1). Angiotensin converting enzyme ${ }^{1}$ ) accounts for the major part of kininase activity in human endothelial cells $(2,3)$. However, the role of other enzymes in the endothelial degradation of kinins is not precisely known. Other pathways of vasoactive peptide degradation in the vascular endothelium may be of particular interest when angiotensin converting enzyme is inhibited. A second kininase $\mathrm{II}^{1}$ ), which is identical to neutral endopeptidase'), has been described in the brush border of the kidney (4) and appears to be involved in the renal degradation of kinins (5). We therefore investigated the presence of neutral endopeptidase and its role in the degradation of bradykinin in cultured human endothelial cells. 


\section{Materials and Methods}

Cell culture

Human umbilical vein endothelial cells were prepared according to the mcthod of Jaffe (6) with minor modifications (7). Cells of the second passage were used throughout all experiments. The purity and identity of the endothelial cell cultures was verified by the presence of factor VIII related antigen (Dako, Hamburg, Germany) and the uptake of fluorescence conjugated-low density lipoprotein (Paesel \& Lorei, Frankfurt, Germany).

Membrane preparation of human umbilical vein endothelial cells

Confluent monolayers were washed with ice-cold $50 \mathrm{mmol} / \mathrm{l}$ Tris- $\mathrm{HCl}$ buffer, scraped off the dish with a rubber policeman and centrifuged at $400 \mathrm{~g}$ for 4 minutes. The cell pellet was lysed with ice-cold distilled water and centrifuged at $56000 \mathrm{~g}$ for 35 minutes. The $56000 \mathrm{~g}$ membrane fraction and the supernatant were aliquotted and frozen immediately. Protein concentration was determined by the method of Lowry et al. (8).

\section{Immunostaining}

Cytocentrifuge preparations of human umbilical vein endothelial cells were stained with an anti-human neutral endopeptidase antibody ALB1 (Dianova, Hamburg, Germany), using the alkaline phosphatase anti-alkaline phosphatase method (9).

Flow cytometry

The endothelial cells were labelled with fluorescence-conjugated ALB1 antibody. Cell counting and quantitation of fluorescence activity of endothelial cells were performed with a flow cytometry analyser (Becton-Dickinson, Heidelberg, Germany).

Assay for neutral endopeptidase activity in endothelial cell fractions

The assay, which has been described in detail by Florentin \& Roques (10), employs dansyl-D-Ala-Gly-Phe $\left(p \mathrm{NO}_{2}\right)$-Gly as the substrate for neutral endopeptidase $\left(K_{\mathrm{m}}=45 \mu \mathrm{mol} / \mathrm{l}, V=0.65\right.$ $\mu \mathrm{mol} / \mathrm{min}$ ). Measurements were performed with $50 \mu \mathrm{mol} / \mathrm{l}$ dansyl- $D$-Ala-Gly-Phe $\left(p \mathrm{NO}_{2}\right)$-Gly in $50 \mathrm{mmol} / \mathrm{l}$ Tris- $\mathrm{HCl}$ buffer in the presence of phosphoramidon $\left(10^{-8} \mathrm{~mol} / \mathrm{l}\right.$, Sigma, München, Germany) or diluent (for total activity) at a $\mathrm{pH}$ of 7.4 and $37^{\circ} \mathrm{C}$ over a period of 24 hours. The increase of fluorogenic activity was measured at $562 \mathrm{~nm}$ with a fluorescence spectrometer (Pharmacia, Freiburg, Germany). Enzymatic activity was defined as the amount of substrate (dansyl-D-Ala-Gly$\mathrm{Phe}\left(\mathrm{pNO} \mathrm{NO}_{2}\right)$-Gly) cleaved at $37^{\circ} \mathrm{C}$ per minute (nmol/min $\cdot \mathrm{mg}$ protein $=\mathrm{mU} / \mathrm{mg}$ protein) and was calculated from the maximal slope of the degradation curve. The activity inhibited by phosphoramidon was assigned to neutral endopeptidase activity.

\section{Degradation of bradykinin}

The degradation of bradykinin was measured using intact endothelial cell monolayers, seeded into $35 \mathrm{~mm}$ dishes (Falcon, Heidelberg, Germany), and grown to confluency. Phosphoramidon $\left(10^{-8} \mathrm{~mol} / \mathrm{l}\right)$, lisinopril, $\left(10^{-6}, \mathrm{ICI}\right.$, Plankstadt, Germany) amastatin ( $10^{-5} \mathrm{~mol} / \mathrm{l}$, Sigma, München, Germany) and $D L$-2-mercaptomethyl-3-guanidinoethyl-thiopropionic acid $\left(10^{-4} \mathrm{~mol} / \mathrm{l}\right.$, Calbiochem, Frankfurt/Main, Germany) were added to the incubation medium (RPMI, $10 \mathrm{~g} / \mathrm{l}$ bovine serum albumin, $10 \mathrm{mmol} / \mathrm{l} \mathrm{HEPES)} 15 \mathrm{~min}$ before the addition of bradykinin stock solution (Sigma, München, Germany) in peptide free medium to a final concentration of $10 \mu \mathrm{g} / \mathrm{l}$ bradykinin.
Samples of $0.3 \mathrm{ml}$ were taken at 15,30 and 60 minutes, mixed with $0.3 \mathrm{ml} 0.2 \mathrm{~mol} / 1$ Tris + $0.01 \mathrm{~mol} / \mathrm{l}$ EDTA buffer (pH 6.4), frozen immediately in liquid nitrogen, and stored at $-70^{\circ} \mathrm{C}$ until further use. In experiments with lisinopril, the bradykinin concentration was determined over an incubation period of 240 minutes. No bradykinin immunorealtivity was detected in the incubation medium, the cell supernatant and the stock solution of the used peptidase inhibitors. No bradykinin degradation was observed in the 4 hour incubation period in cell free incubation medium at $37^{\circ} \mathrm{C}$.

\section{Bradykinin radioimmunoassay}

Immunoreactive kinins were measured by a radioimmunoassay (RIA) as described previously $(10,11)$. The minimal amount of bradykinin distinguishable from zero was $2 \mathrm{pg}$ and thus the detection limit of the RIA was $20 \mathrm{ng}$ per litre of cell supernatant medium. The inter- and intra-assay coefficients of variation were $4 \%$ and $5 \%$, respectively. The cross reactivity was less than $1 \%$ to des-9arg-bradykinin. The peptidase inhibitors added to the incubation medium did not interfere with the RIA at the concentrations used in the experiments.

\section{Calculations and statistics}

Experiments were performed in triplicate. Results are shown as means \pm SEM ( $n=$ number of dishes or experiments). The bradykinin half-life was calculated by linear regression analysis in each experiment from the degradation of bradykinin during the first 60 minutes. In experiments with lisinopril, the half-life was calculated from the bradykinin degradation during the first 240 minutes. Statistical significance was analysed by the MannWhitney-U Test for unpaired samples. $\mathrm{P}$ values less than 0.05 were accepted as statistically significant.

\section{Results}

\section{Immunohistochemistry}

Staining with the anti-human neutral endopeptidase antibody demonstrated the presence of neutral endopeptidase antigen (fig. 1). Control staining without the anti-neutral endopeptidase antibody resulted in low unspecific binding of the alkaline-phosphatase complex. Flow cytometry analysis showed that $67 \pm 6 \%(n=4)$ of endothelial cells express neutral endopeptidase antigen on their cell membrane.

\section{Neutral endopeptidase activity}

The activity of endothelial neutral endopeptidase was measured in the $56000 \mathrm{~g}$ crude membrane preparation of human umbilical vein endothelial cells. In the membrane preparation, a neutral endopeptidase activity of $167 \pm 1.7 \mu \mathrm{U} / \mathrm{mg}$ protein (mean values $\pm \mathrm{SEM}$; $\mathrm{n}=6$ ) was measured. No neutral endopeptidase activity was detected in the supernatant of the $56000 \mathrm{~g}$ fraction, which mainly consists of cytosolic particles (fig. 2). 


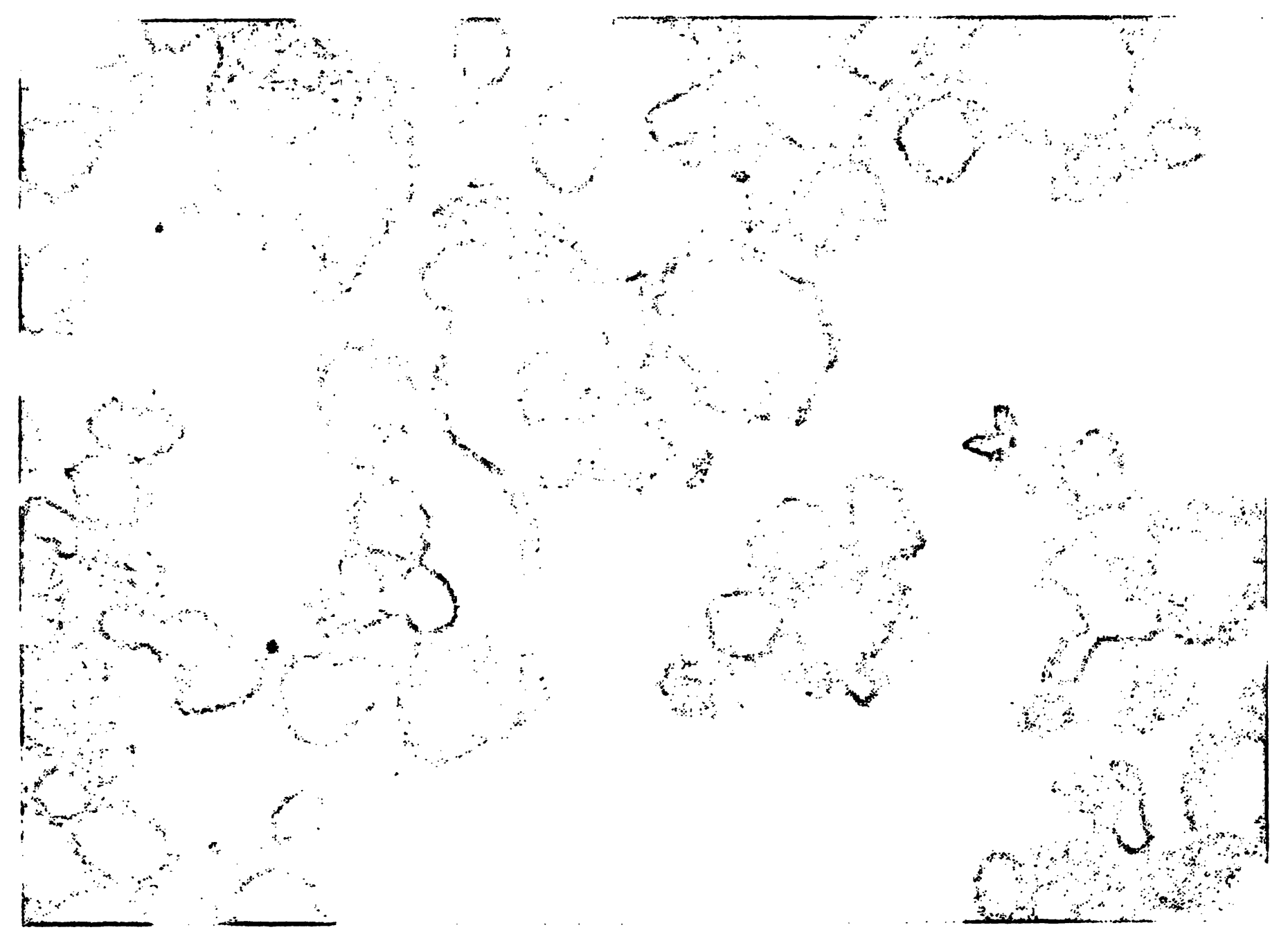

Fig. 1. Light micrograph of human umbilical vein endothelial cells stained with an antibody directed against neutral endopeptidase (haematoxylin stain, magnification $\times 200$ ).

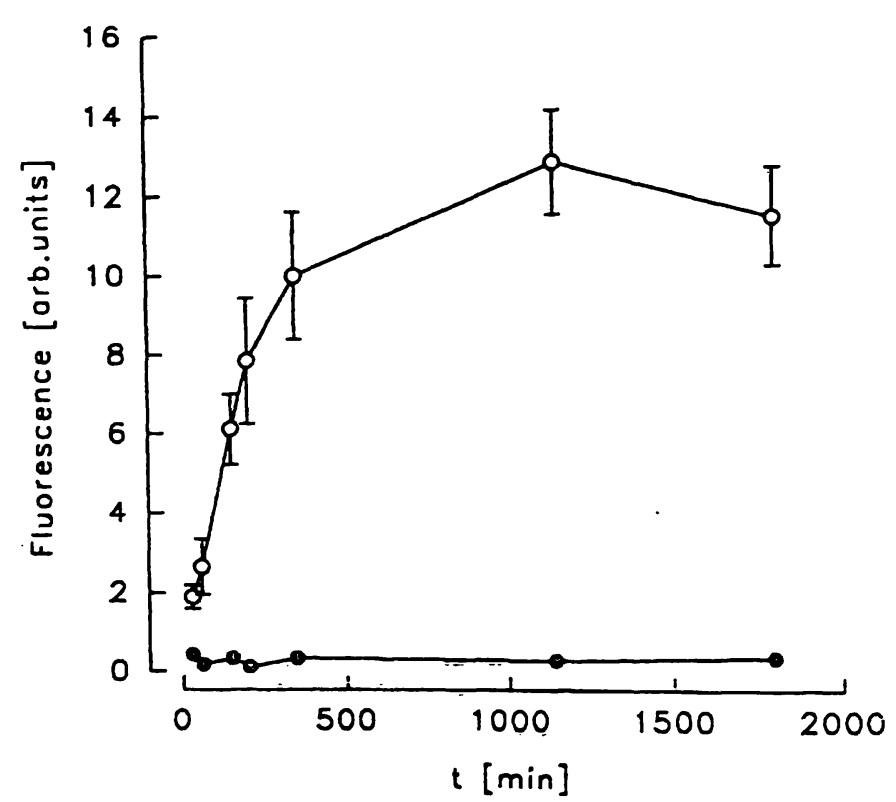

Fig. 2. Time course of dansyl-D-Ala-Gly-Phe $\left(p \mathrm{NO}_{2}\right)$-Gly $(50$ $\mu \mathrm{mol} / \mathrm{l})$ degradation by crude membrane preparation of human umbilical vein endothelial cells $(56000 \mathrm{~g}$ fraction) (0) and the cytosol fraction $(\bullet)(n=6$ each) in $50 \mathrm{mmol} / \mathrm{l}$ Tris-HCl buffer, $\mathrm{pH} 7.4$, at $37^{\circ} \mathrm{C}$. Data represent the specific neutral endopeptidase activity, which was inhibited by phosphoramidon $\left(10^{-8} \mathrm{~mol} / 1\right)$.

\section{Endothelial degradation of bradykinin}

In the supernatant of confluent endothelial monolayers, the decrease of $10^{-8} \mathrm{~mol} / \mathrm{l}$ exogeneous bradykinin shows a time dependent kinetic (fig. 3 ) in the absence of inhibitors. The rapid degradation during the first 15 minutes is followed by a slow degradation during the following time period. In the presence of phosphoramidon $\left(10^{-8} \mathrm{~mol} / \mathrm{l}\right)$ significantly higher bradykinin concentrations were measured in the superna: tant of human umbilical vein endothelial cells compared with the control $(\mathrm{p}<0.05, \mathrm{n}=9$ ). The angiotensin converting enzyme inhibitor, lisinopril, inhibited most of the bradykinin degradation by intact endothelial monolayers. After $240 \mathrm{~min}$ incubation with phosphoramidon in the presence of lisinopril, the bradykinin concentration was significantly higher than after incubation with lisinopril alone (lisinopril: $3680 \pm 458 \mathrm{ng} / \mathrm{l}, \mathrm{n}=12$ ); lisinopril + phosphoramidon: $5060 \pm 568 \mathrm{ng} / \mathrm{l}, \mathrm{n}=9$; $\mathrm{p}<0.03$ vs. lisinopril). 


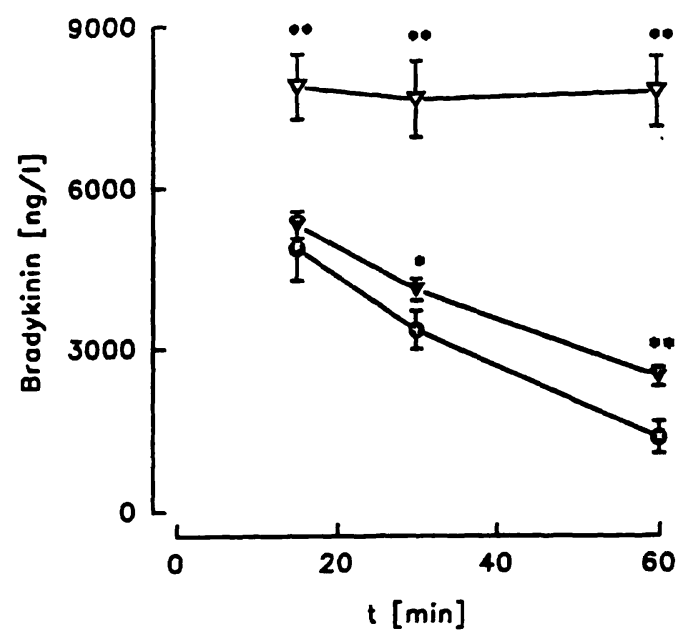

Fig. 3. Time course of degradation of exogeneous bradykinin in the absence (control, circle) and presence of lisinopril $\left(10^{-6} \mathrm{~mol} / \mathrm{l}\right.$, filled triangle), phosphoramidon $\left(10^{-8}\right.$ $\mathrm{mol} / \mathrm{l}$, open triangle) and the combination of phosphoramidon and lisinopril in the supernatant of a confluent monolayer of endothelial cells (human umbilical vein endothelial cells; $\mathrm{n}=9-16, *=\mathrm{P}<0.05$ vs. control, ${ }^{* *}=\mathrm{P}<0.01$ vs. control).

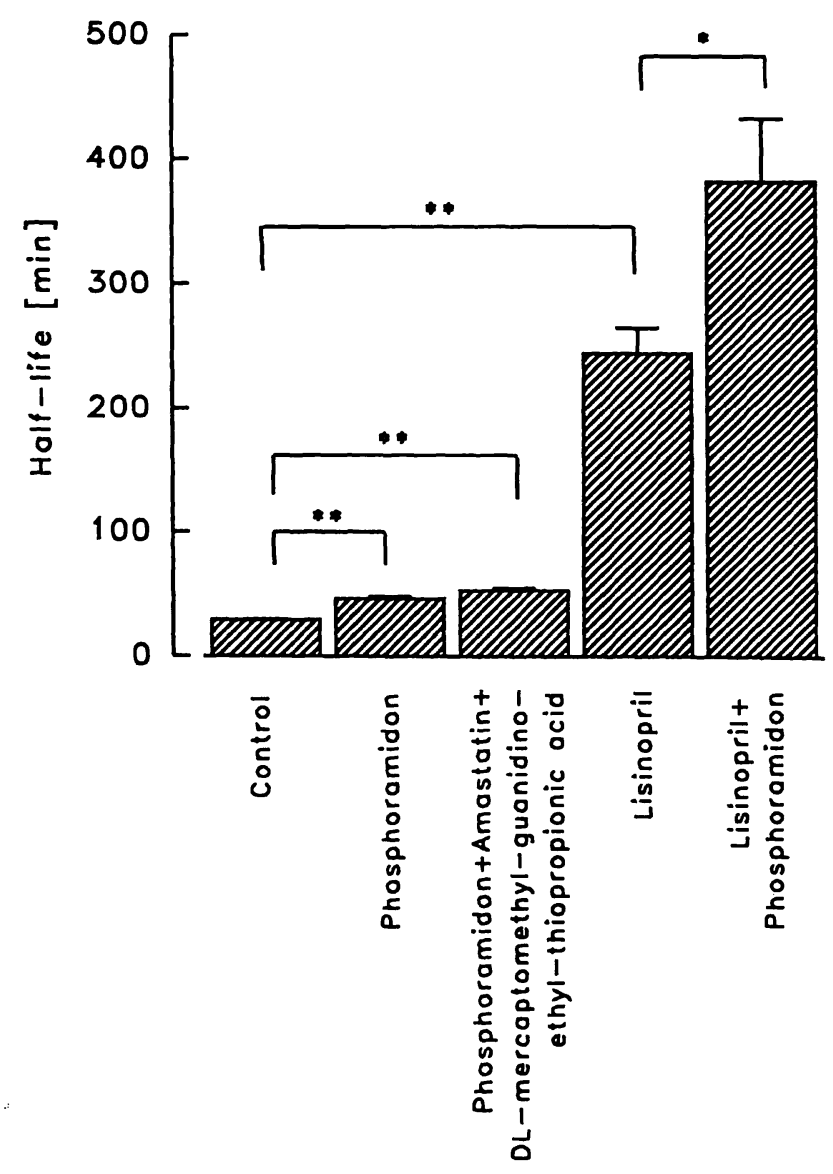

Fig. 4. Half-lives of bradykinin in the presence or absence of various peptidase inhibitors phosphoramidon, $10^{-8}$ $\mathrm{mol} / \mathrm{l}$; lisinopril, $10^{-6} \mathrm{~mol} / \mathrm{l}$; amastatin, $10^{-6} \mathrm{~mol} / \mathrm{l} ; D L$ mercaptomethyl-guanidinoethyl-thiopropionic acid, $10^{-4} \mathrm{~mol} / \mathrm{l}$; mean \pm SEM minutes; $*=\mathrm{P}<0.05 \mathrm{vs}$. control, ${ }^{* *}=\mathrm{P}<0.01$ vs. control.
The half-life of bradykinin in the absence of inhibitors was $29 \pm 1$ minutes $(n=18)$ and it was prolongated up to $244 \pm 20$ minutes $(n=15, p<0.005)$ in the presence of the angiotensin converting enzyme inhibitor, lisinopril. Phosphoramidón alone significantly prolonged the half-life of bradykinin up to $46 \pm 2$ minutes ( $\mathrm{n}=15, \mathrm{p}<0.01$; fig.4). The addition of phosphoramidon to lisinopril resulted in a significant prolongation of the half-life up to $381 \pm 51$ minutes ( $\mathrm{n}=12, \mathrm{~L}$ vs. $\mathrm{L}+\mathrm{P} \mathrm{p}<0.03$ ). The half-life of bradykinin in the presence of all inhibitors (lisinopril, amastatin, phosphoramidon, $D L$-2-mercaptomethyl3-guanidinoethyl-thiopropionic acid) did not exceed the half-life of bradykinin in the presence of the combination of lisinopril and phosphoramidon $(\mathrm{L}+\mathrm{P}+\mathrm{A}: \quad 386 \pm 52$ minutes, $\mathrm{n}=12$ $\mathrm{L}+\mathrm{P}+\mathrm{A}+\mathrm{M}: 275 \pm 22$ minutes, $\mathrm{n}=9$ ). The combination of both inhibitors with amastatin and $D L$-2-mercaptomethyl-3-guanidinoethyl-thiopropionic acid affected the half-life of bradykinin.

It is estimated that the degradation of bradykinin by neutral endopeptidase, as judged from the prolongation of the bradykinin half-life, is equivalent to about $9 \%$ of the degradation due to angiotensin converting enzyme activity.

\section{Discussion}

Our study shows that two kininases are largely responsible for the degradation of the vasoactive peptide, bradykinin, by intact endothelial cells in culture, i.e. angiotensin converting enzyme and neutral endopeptidase. The decay of the bradykinin concentration indicated that about $90 \%$ of bradykinin is degraded by angiotensin converting enzyme, whereas the minor part is cleaved by neutral endopeptidase. Aminopeptidase $^{1}$ ) or carboxypeptidase ${ }^{1}$ ) activity seems not to play a role in bradykinin degradation by intact endothelial cells.

In order to verify the presence of neutral endopeptidase we performed alkaline phosphatase staining of human endothelial cells with a monoclonal mouse antibody. Quantification by flow cytometry analysis performed with the same antibody detected $67 \%$ antigen-positive cells. Since the antibody was incubated with intact living cells and could not penetrate the cellular membrane this result indicates the presence of neutral endopeptidase on the surface of endothelial cells.

This corresponds to the results of the functional assay with the artificial substrate, dansyl-D-Ala-Gly$\mathrm{Phe}\left(p \mathrm{NO}_{2}\right)$-Gly, which show considerable neutral endopeptidase-activity in the membrane preparations of 
human endothelial cells. Neutral endopeptidase activity was not, however, detected in the cytosolic fraction. The lack of detectable neutral endopeptidase activity in the soluble fraction indicates that this peptidase is mainly located in the cellular membranes of the endothelial cell, where it is in close contact with circulating peptides. The enzymatic activity measured in the membrane preparation corresponds to previously published data of Florentin and coworkers for various rat tissues (10).

The vascular endothelium plays an important role in the regulation of the vascular tone. We used the confluent living endothelial monolayer to study the degradation of physiologically effective concentrations of bradykinin, a potent vasodilator. Our data show that living endothelium degrades bradykinin by enzymatic cleavage, and that this was prevented by two specific inhibitors. The neutral endopeptidase inhibitor, phosphoramidon, significantly diminished the bradykinin degradation after 30 and 60 minutes, although angiotensin converting enzyme activity was not blocked. The time curve of bradykinin degradation indicates that the major decrease during the first 30 minutes is not observed in the presence of the angiotensin converting enzyme inhibitor, lisinopril. We therefore attributed this fall of bradykinin concentration to the dominant role of angiotensin converting enzyme in the endothelial bradykinin degradation.

By calculating the half-life of bradykinin in presence of intact endothelium, we detected a significant effect of phosphoramidon. This effect was pronounced when the angiotensin converting enzyme inhibitor, lisinopril, was present, indicating a physiological role of neutral endopeptidase in the degradation of bradykinin during angiotensin converting enzyme inhibition. The combination of lisinopril and phosphoramidon almost prevented the bradykinin degradation, indicating the presence of a low undefined additional

\section{References}

1. Peach, M. J., Singer, H. A. \& Loeb, A. L. (1985) Mechanisms of endothelium-dependent vascular smooth muscle relaxation. Biochem. Pharmacol. 34, 1867-1874.

2. Johnson, A. R. \& Erdös, E. G. (1977) Metabolism of vasoactive peptides by human endothelial cells in culture. J. Clin. Invest. 59; 684-695.

3. Yang, H. Y. T., Erdös, E. G. \& Levin, Y. (1971) Characterization of a dipeptidylhydrolase (kininase II; angiotensin I converting enzyme). J. Pharmacol. Exp. Ther. 177, 291 300.

4. Kerr, M. A. \& Kenny, A. J. (1974) The purification and specifity of a neutral endopeptidase from rabbit kidney brush border. Biochem. J. 134, 477-488; Biochem. Pharmacol. 34, 1867-1874. kininase activity on intact endothelial cells. These activities cannot be attributed to aminopeptidase or carboxypeptidase, since their inhibitors, amastastin and $D L$-2-mercaptomethyl-3-guanidinoethyl-thiopropionic acid, are without effect. The present data are consistent with the hypothesis of an additional role of endothelial neutral endopeptidase in the local degradation of bradykinin, besides angiotensin converting enzyme, in intact endothelium.

In a recently published study (13), which investigated bradykinin-induced vascular permeability in the hamster cheek pouch, phosphoramidon, as well as the angiotensin converting enzyme inhibitor, captopril, significantly augmented the effect of bradykinin on vascular leakage. Furthermore, neutral endopeptidase located in the vascular endothelium is involved in the cleavage of several other vasoactive peptides including substance $\mathrm{P}$, chemotactic peptide (N-Formyl-MetLeu-Phe), endothelin and angiotensin I (1, 14-18). Recently, Solheilac and coworkers identified neutral endopeptidase as a $M_{\mathrm{r}} 94000$ membrane protein in vascular membranes from rat and rabbit aorta. In addition, they demonstrated the degradation of atrial natriuretic peptide by neutral endopeptidase (19).

Thus, the neutral endopeptidase, which is present in membranes of human endothelial cells, may contribute to the local degradation of bradykinin and other vasoactive peptides by the vascular endothelium, particularly when angiotensin converting enzyme inhibitors are present.

\section{Acknowledgement}

The authors would like to thank Ms Uschi Meisel-Rott, Ms Kerstin Kunkel and Ms Karen Vetter for excellent technical assistance.

The results were presented in part at the scientific sessions of the American Heart Association 1991.
5. Ishida, H., Scicli, A. G. \& Carretero, O. A. (1989) Role of angiotensin converting enzyme and other peptidases in in vivo metabolism of kinins. Hypertension 14, 332-327.

6. Jaffe, E. A., Nachman, R. L., Becker, C. G. \& Minick, C. R. (1973) Culture of human endothelial cells derived from umbilical veins. Identification by morphologic and immunologic criteria. J. Clin. Invest. 52, 274 -2756.

7. Franke, R. P., Gräfe, M., Schnittler, H., Seiffge, D., Mittermayer, C. \& Drenckhahn, D. (1984) Induction of human vascular endothelial stress fibres by fluid shear stress. Nature $307,648-649$.

8. Lowry, O. H., Rosebrough, N. H., Farr, A. L. \& Randall, R. J. (1951) Protein measurement with Folin phenol reagent. J. Biol. Chem. 193, 265-279. 
9. Cordell, J., Falini, B., Erber, O. N., Gosh, A. K., Abdulaziz Z., MacDonald, S., Polford, K., Stein, H. \& Mason, D. Y. (1984) Immunoenzymatic labeling of monoclonal antibodies using immune complexes of alkaline phosphatase and monoclonal anti-alkaline phosphatase (APAAP complexes). J. Histochem. Cytochem. 32, 219-227.

10. Florentin, D., Sassi, A. \& Roques, B. P. (1984) A highly sensitive fluorometric assay for "enkephalinase", a neutral metalloendopeptidase, that releases tyrosine-glycine-glycine from enkephalins. Analytical Biochem. 141, 62-69.

11. Proud, D., Togias, A., Naclerio, R. M., Crush, S. A. Norman, P. S. \& Liechtenstein (1983) Kinins are generated in vivo following nasal airway challenge of allergic individuals with allergen. J. Clin. Invest. 72, 1678-1685.

12. Graf, K., Bossaller, C., Auch-Schwelk, W., Gräfe, M., Baumgarten, C. R. \& Fleck, E. (1991) ACE-inhibitors diminish the degradation of bradykinin and enhance the endothelium-dependent relaxations in isolated coronary arteries. Pharm. Pharmacol. Lett. 1,71-73.

13. Yong, T., Gao, X. P., Koizumi, S., Conlon, M., Rennard, S. I., Mayhan, W. G. \& Rubinstein, I. (1992) Role of peptidases in bradykinin-induced increase in vascular permeability in vivo. Circ. Res. 70, 952-959.

14. Stephenson, S. L. \& Kenny, A. J. (1987) The hydrolysis of a human ațrial natriuretic peptide by pig kidney microvillar membranes is initiated by endopeptidase 24.11. Biochem. J. 243, 183-187.
15. Matsum̆ura, Y., Ikegawa, R., Tsukahara, Y., Takaoka, M. \& Morimoto, S. (1990) Conversion of big endothelin-1 to endothelin-1 by two types of metalloproteinases derived from porcine aortic endothelial cells. FEBS Lett. 272, 166170.

16. Abassi, Z. A. \& Keiser, H. R. (1991) Effects of neutral endopeptidase inhibition on the excretion of endothelin. Hypertension 18, 405 (Abstract).

17. Gafford, J. T., Skidgel, R. A., Erdös, E. G. \& Hersh, L. B. (1983) Human kidney "Enkephalinase", a neutral metalloendopeptidase that cleaves active peptides. Biochemistry $22,3265-3271$.

18. Erdös, E. G., Wagner, B., Harbury, C. B., Painter, R. G., Skidgel, R. A. \& Fa, X. G. (1990) Down-regulation and inactivation of neutral endopeptidase 24.11 (Enkephalinase) in human neutrophils. J. Biol. Chem. 264, 1451914523.

19. Soleilhac, J. M., Lucas, E., Beaumont, A., Turcaud, S., Michel, J. B., Ficheux, D., Fournie-Zaluski, M. B. \& Roques, B. P. (1992) A 94-kDA protein, identified as neutral endopeptidase-24.11, can inactivate atrial natriuretic peptide in the vascular endothelium. Mol. Pharmacol. 41, $609-614$.

Dr. Kristof Graf

German Heart Institute Berlin

Department of Cardiology

Augustenburger Platz 1

W-1000 Berlin 65

Germany 